\title{
Drastic Shift From Positive to Negative Estrogen Effect on Bone Morphogenetic Protein Signaling in Pulmonary Arterial Endothelial Cells Under Hypoxia
}

\author{
Hiroaki Ichimori, MD; Shigetoyo Kogaki, MD; Kunihiko Takahashi, MD, PhD; \\ Hidekazu Ishida, MD, PhD; Jun Narita, MD; Nobutoshi Nawa, MD; Hiroki Baden, MD; \\ Toshiki Uchikawa, MD; Yoko Okada, MD; Keiichi Ozono, MD, PhD
}

\begin{abstract}
Background: To investigate the possible role of sex hormones in the pathogenesis of pulmonary arterial hypertension (PAH), the effect of $\beta$-estradiol (E2) on bone morphogenetic protein (BMP) signaling, a key signaling pathway involved in $\mathrm{PAH}$, was studied in human pulmonary arterial endothelial cells (HPAEC).
\end{abstract}

Methods and Results: BMP signaling molecules, including BMP receptor, Smad1/5/8 and Id1, were studied in HPAEC under $1 \% \mathrm{O}_{2}$ (hypoxia) and $21 \% \mathrm{O}_{2}$ (normoxia) as well as the effect of hypoxia-inducible factor (HIF)-1a expression in the presence of E2 on BMP signaling. The effects of an estrogen receptor (ER) antagonist (ICI 182,780) and cycloheximide, and the interaction of ER with Smad or HIF-1a were also studied. In the presence of E2, BMP signaling was augmented under normoxia but suppressed under hypoxia. HIF-1a accumulation suppressed BMP signaling, whereas HIF-1a inhibition augmented signaling. These effects were cancelled by ICI 182,780. Moreover, binding between ER, HIF-1 $a$ and phosphorylated (p)-Smad1/5/8 proteins occurred only under hypoxia. On inhibition of de novo synthesis with cycloheximide, however, $p-S m a d 1 / 5 / 8$ expression was suppressed only under normoxia.

Conclusions: The effects of E2 on BMP signaling in HPAEC altered depending on $\mathrm{O}_{2}$ concentration and different mechanisms may be involved. BMP and sex hormones may play an important role in PAH development. (Circ $J$ 2013; 77: 2118-2126)

Key Words: Bone morphogenetic protein; Estrogen; Hypoxia-inducible factor

$\mathbf{P}$ ulmonary arterial hypertension $(\mathrm{PAH})$ is characterized by pulmonary artery remodeling wherein small peripheral pulmonary arteries are occluded, pulmonary arterial pressure increases, and eventually right heart failure occurs. ${ }^{1,2}$ Recent studies have identified the involvement of diverse vascular effectors in the pathogenesis of PAH, such as genetic background, growth factors, and environmental stress. Bone morphogenetic protein receptor $(B M P R) 1 \mathrm{~B},{ }^{3}$ activin receptor-like kinase $(A L K) 1,{ }^{4}$ and $\operatorname{Smad} 8^{5}$ mutations as well as $B M P R 2$ mutation have been reported in idiopathic $\mathrm{PAH}$ patients. Because the gene for $B M P R 2$ was identified as one of those responsible for familial ${ }^{6,7}$ and idiopathic ${ }^{8} \mathrm{PAH}$, the involvement of BMPR2 in the signal pathway in PAH development has been strenuously investigated. The possibility of PAH development in family members of patients harboring $B M P R 2$ mutants is only $10-20 \%$, and loss of BMPR2 expression in idiopathic PAH occurs even in the absence of $B M P R 2$ gene mutations. ${ }^{9}$ Therefore, heterozygous $B M P R 2$ mutations are by themselves insufficient to account for the clinical manifestations of idiopathic $\mathrm{PAH}$, and multiple environmental or genetic "hits" may play a pivotal role in triggering the disease.

\section{Editorial p 1992}

PAH is estimated to affect 2-3 individuals/million per year, and the incidence of idiopathic PAH in young women is approximately twice that of age-matched men (male:female ratio, $1: 2.3$ ). Austin et al reported that the ratio of male to female in 351 PAH patients with BMPR2 mutations was 98:253, showing an overwhelming proportion of female subjects. ${ }^{10}$ According to a report by Rosenzweig et al, 23 (16\%) of $147 \mathrm{PAH}$ patients had BMPR2 mutations and the male:female ratio was 5:18. ${ }^{11}$ Despite much epidemiological evidence, the reason for this female predominance remains unclear. Although estrogen

Received August 2, 2012; revised manuscript received February 27, 2013; accepted March 28, 2013; released online May 18, 2013 Time for primary review: 31 days

Department of Pediatrics, Osaka University Graduate School of Medicine, Suita, Japan

Mailing address: Shigetoyo Kogaki, MD, Department of Pediatrics, Osaka University Graduate School of Medicine, 2-2 Yamadaoka, Suita 565-0871, Japan. E-mail: skogaki@ ped.med.osaka-u.ac.jp

ISSN-1346-9843 doi:10.1253/circj.CJ-12-0997

All rights are reserved to the Japanese Circulation Society. For permissions, please e-mail: cj@j-circ.or.jp 
seems to play an important role in the progression of various pulmonary diseases, such as acute lung injury and chronic obstructive pulmonary disease, its role in the pathogenesis and progression of PAH remains controversial. 1,6,12,13

BMPR2 is a constitutively active serine-threonine kinase that heterodimerizes with and phosphorylates a type I receptor in the presence of a BMP ligand. The activated type I receptor phosphorylates Smad proteins at the $\mathrm{C}$ terminus (Smad1, 5, and 8), which then translocate to the nucleus in the presence of a common partner Smad, Smad4, to regulate gene transcription. A major transcriptional target is the inhibitor of the DNAbinding (Id) family of proteins, of which Id1-4 play a central role in the regulation of gene expression, and thus in cellular differentiation and proliferation in response to BMP. ${ }^{14}$ In the present study, we refer to the BMPR-Smad1/5/8-Id1 signal pathway as "BMP signaling". Although defective BMP-mediated regulation of cell differentiation and turnover could contribute to abnormal vascular remodeling, the precise mechanism of BMP signaling in this event is unclear.

We previously demonstrated that the expression of BMPR2, phosphorylated (p)-Smad1/5/8, and Id1 was reduced in the lung tissue of hypoxia-exposed Sprague-Dawley rats and hypoxia-exposed rat lung vascular endothelial cells. ${ }^{15}$ Both in vivo and in vitro, reduced expression of BMP signaling was predominantly observed in pulmonary arterial endothelial cells (PAEC). Smad1/5/8 and $\mathrm{p}-\mathrm{Smad} 1 / 5 / 8$ expression was also reduced in PAEC of PAH patients. ${ }^{16}$ Endothelial dysfunction and proliferation may contribute to $\mathrm{PAH}$ and vascular remodeling. ${ }^{17}$ Thus, we suggest that hypoxia induces changes in intracellular BMP signaling in PAEC, which are involved in the pathogenesis of $\mathrm{PAH}$, and exposure to hypoxia can mimic the pathogenesis of PAH in vitro. Moreover, reduced expression of BMPR2 has also been found in the lung tissue of monocrotaline-induced pulmonary hypertensive rats. ${ }^{18}$ In this study, we focused on hypoxia-inducible factor (HIF)- $1 \alpha$. HIF- $1 \alpha$ is an oxygen-dependent transcription factor that regulates the expression of several genes in response to hypoxia. Not only BMPR 2 and $p-S m a d 1 / 5 / 8$ but also HIF- $1 \alpha$ is mainly localized in PAEC of PAH patients. ${ }^{19}$

We hypothesized that estrogen and HIF- $1 \alpha$ may contribute to PAH development via BMP signaling as components of the multiple epidemiological factors. We found a positive effect of $\beta$-estradiol (E2) on BMP signaling in human PAEC (HPAEC) under normoxia and negative effect under hypoxia, and showed that E2-induced de novo synthesized protein is involved in this positive effect, and interaction of the estrogen receptor $(\mathrm{ER})$ with $\mathrm{HIF}-1 \alpha$ is involved in this negative effect.

\section{Methods}

\section{Materials}

HPAEC were obtained from Cambrex (Walkersville, MD, USA). Human recombinant BMP2 was purchased from R\&D Systems (Minneapolis, MN, USA), E2 and cycloheximide (CHX) from Wako Pure Chemical Industries (Osaka, Japan), ICI 182,780 from Tocris Bioscience (Ellisville, MO, USA) and YC-1 from Chemicon (Billerica, MA, USA). Anti-pSmad1/5/8 antibody was purchased from Cell Signaling Technology (Beverly, MA, USA), anti-Smad1 antibody from Santa Cruz Biotechnology (Santa Cruz, CA, USA), anti-HIF-1 $\alpha$ antibody from Novus Biologicals (Littleton, CO, USA), anti-ER $\alpha$ antibody from Abcam (Cambridge, MA, USA) and anti- $\beta$ actin antibody from Sigma Chemical (St. Louis, MO, USA).

\section{Cell Culture}

HPAEC were grown in Endothelial basal medium (Cell Applications, San Diego, CA, USA). All experiments were performed using subconfluent cultures of the same batch derived from pooled donors, and were used only between passages 3 and 7. These cells were incubated at $37^{\circ} \mathrm{C}$ in a humidified atmosphere of $5 \% \mathrm{CO}_{2}$ and air. For exposure to hypoxia, subconfluent cells were placed in an APM-30D incubator (Astec, Fukuoka, Japan) at $37^{\circ} \mathrm{C}$ in a humidified atmosphere of $1 \%$ $\mathrm{O}_{2} / 5 \% \mathrm{CO}_{2} / 94 \% \mathrm{~N}_{2}$. Cells were grown to subconfluence and the medium was changed to phenol-red free serum-starved DMEM. After overnight quiescence, cells were treated for $12 \mathrm{~h}$ with $50 \mathrm{ng} / \mathrm{ml} \mathrm{BMP} 2$ in phenol-red free serum-starved medium with or without $\mathrm{E} 2$ under $21 \% \mathrm{O}_{2}$ (normoxia) and $1 \%$ $\mathrm{O}_{2}$ (hypoxia).

\section{Constructs and Luciferase Reporter Assay}

The constitutively active HIF- $1 \alpha$ expression vector pcDNA3 was kindly provided by Dr Hirota (Kyoto University), ${ }^{20,21}$ the -2.1-kb Id1 promoter linked to a luciferase reporter gene (pGL1-Luc) by Dr Katagiri (Saitama Medical University), ${ }^{22}$ and the pCMV-estrogen response element (ERE)-luciferase was constructed by Dr Makishima (Nihon University). ${ }^{23}$ Transient transfection was carried out using Lipofectamine (Invitrogen, Carlsbad, CA, USA) according to the manufacturer's protocol. The total amount of DNA added to each well was equalized using an empty vector. The luciferase assay was performed in triplicate according to the protocol of the dual luciferase reporter assay system (Promega, Madison, WI, USA). Briefly, 2 days after transfection, cells were cultured with BMP2 and/or $\mathrm{E} 2$ and incubated under $1 \% \mathrm{O}_{2}$ (hypoxia) or $21 \% \mathrm{O}_{2}$ (normoxia). Twelve hours later, cells were lysed and luciferase activity was determined using specific substrates in a luminometer. Transfection efficiency was normalized by co-transfection with tK-Renilla luciferase construct (Promega). ${ }^{24}$

\section{Western Blot Analysis}

Cells were cultured in 60 -mm dishes and, after overnight quiescence, were incubated with BMP2 $(50 \mathrm{ng} / \mathrm{ml})$ and/or E2 $\left(10^{-7} \mathrm{~mol} / \mathrm{L}\right)$ in a phenol red-free serum-free medium for $12 \mathrm{~h}$ under $1 \%$ or $21 \% \mathrm{O}_{2}$. To prepare whole-cell lysates, cells were washed twice with ice-cold PBS and solubilized in lysis buffer. Lysates were centrifuged at $12,000 \mathrm{~g}$ for $20 \mathrm{~min}$ at $4^{\circ} \mathrm{C}$ and supernatants were collected. For cell fractionation, cells were washed twice with ice-cold PBS and solubilized in a hypotonic lysis buffer. Lysates were centrifuged at $12,000 \mathrm{~g}$ for $20 \mathrm{~min}$ and supernatants were used as cytosol extracts. The pellet was then lysed with a hypertonic buffer and supernatants were collected after centrifugation $(12,000 \mathrm{~g}$ for $20 \mathrm{~min}$ ) for use as nuclear extracts. The lysis buffers have been described previously. ${ }^{24}$ The protein concentration was determined by the Lowry method using DC reagent (Bio-Rad Laboratories, Hercules, CA, USA). The same amount of sample was separated with sodium dodecylsulfate polyacrylamide gel electrophoresis (SDS-PAGE) and transferred electrophoretically to nitrocellulose membranes. Membranes were blocked in 5\% BSA in Tris-buffered saline (TBS). The membranes were then immunoblotted with anti-p-Smad1/5/8 (1:1,000), anti-Smad1 (1:500) or anti- $\beta$-actin $(1: 4,000)$, and developed with horseradish peroxidase-coupled anti-mouse IgG antibody, followed by enhancement with SuperSignal West Dura Extended Duration Substrate antibodies (Pierce, Rockford, IL, USA). The protein bands were digitally imaged for densitometry using ImageJ (National Institutes of Health, Bethesda, MD, USA). 
(A)
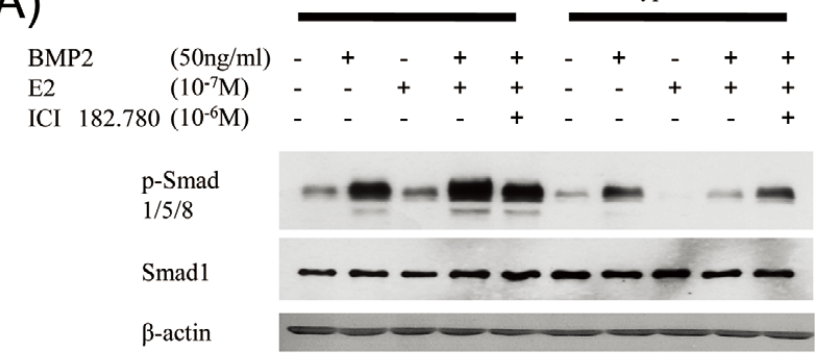

(B)

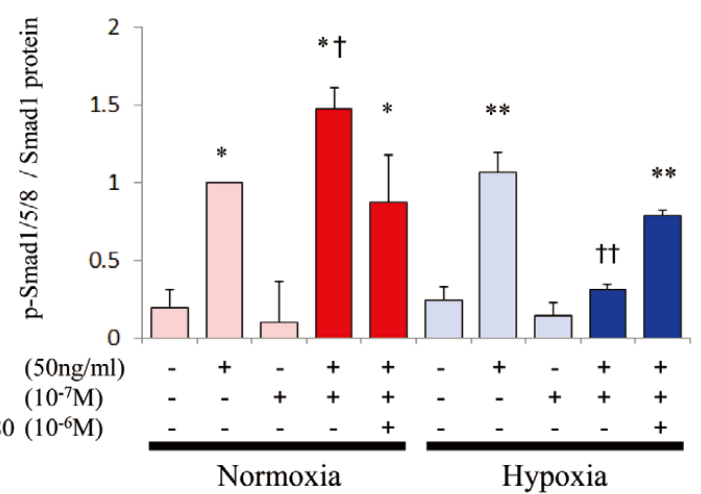

(C)

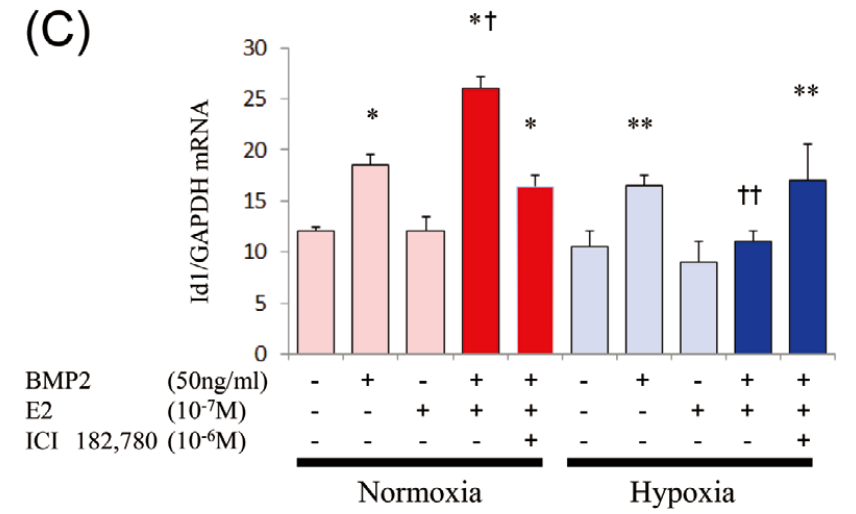

BMP2
E2

ICI $182,780\left(10^{-6} \mathrm{M}\right)$

Normoxia

Hypoxia
(D)

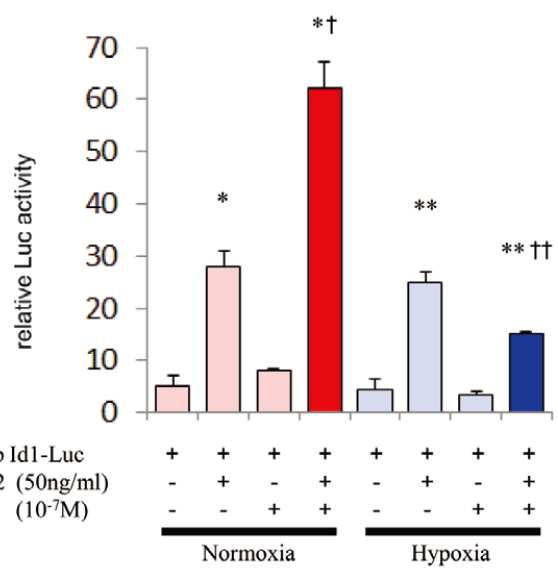

Figure 1. Effects of estrogen on bone morphogenetic protein (BMP) signaling. (A) Western blot analysis for $p-S m a d 1 / 5 / 8$, Smad1 and $\beta$-actin proteins. (B) Representative expression of $\mathrm{p}$-Smad1/5/8. Relative intensities of the bands were determined by densitometry. Density of p-Smad1/5/8 was normalized against that of Smad1. (C) Quantitative RT-PCR analysis of mRNA expression of Id1. Data were normalized by the expression of GAPDH. (D) Id1 promoter assay in the presence of BMP2 and/or $\beta$-estradiol (E2) under normoxia or hypoxia. Results are presented as the fold induction of luciferase (Luc) activity. Under normoxia, (A,B) pSmad1/5/8 proteins, (C) Id1 mRNA, and (D) Id1 transcriptional activity were significantly increased after the addition of both BMP2 and E2 compared with BMP2 alone, and augmentation of $(\mathbf{A}, \mathbf{B})$ p-Smad1/5/8 proteins and (C) Id1 mRNA with BMP2 and E2 treatment was inhibited by the addition of ICI 182,780. Under hypoxia, (A,B) p-Smad1/5/8 proteins, (C) Id1 mRNA, and (D) Id1 transcriptional activity were significantly decreased after the addition of both BMP2 and E2 compared with BMP2 alone, and the decrease in $(\mathbf{A}, \mathbf{B}) \mathrm{p}$-Smad1/5/8 proteins and $(\mathbf{C}) \mathrm{Id} 1 \mathrm{mRNA}$ with BMP2 and E2 treatment was recovered by the addition of $\mathrm{ICl}$ 182,780. Error bars represent SD. ${ }^{*} \mathrm{P}<0.05$ compared with vehicle under normoxia. ${ }^{* *} \mathrm{P}<0.05$ compared with vehicle under hypoxia. ${ }^{\dagger} \mathrm{P}<0.05$ compared with BMP2 alone under normoxia. ${ }^{\dagger+} \mathrm{P}<0.05$ compared with BMP2 alone under hypoxia. Results are representative of at least 3 separate experiments.

\section{Co-Immunoprecipitation Analysis}

Lysates were precipitated with anti-ER $\alpha$ or anti-HIF- $1 \alpha$ antibody (1:100) at $4^{\circ} \mathrm{C}$ for $1 \mathrm{~h}$. Protein-antibody complexes were bound to protein G-Sepharose (Sigma) for $1 \mathrm{~h}$, washed extensively with TBS-Tween $(0.1 \%)$, eluted with buffer as mentioned in Western Blot Analysis, resolved by SDS-PAGE and detected on western blot.

\section{RNA Preparation and Real-Time Reverse Transcription- Polymerase Chain Reaction (RT-PCR)}

Total RNA was prepared using the RNeasy Mini Kit (Qiagen, Hilden, Germany) according to the manufacturer's instructions, and reverse transcribed using the High Capacity cDNA Reverse Transcription Kit (Applied Biosystems, Foster City, CA, USA) according to the manufacturer's instructions. Quantita- 
(A)

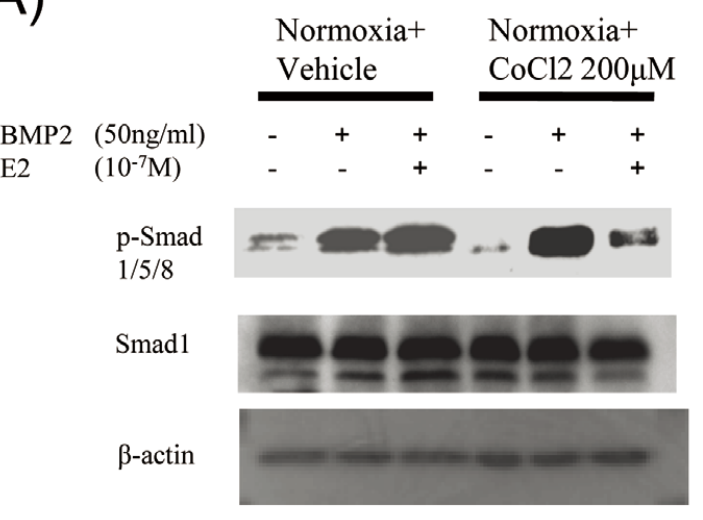

(C)

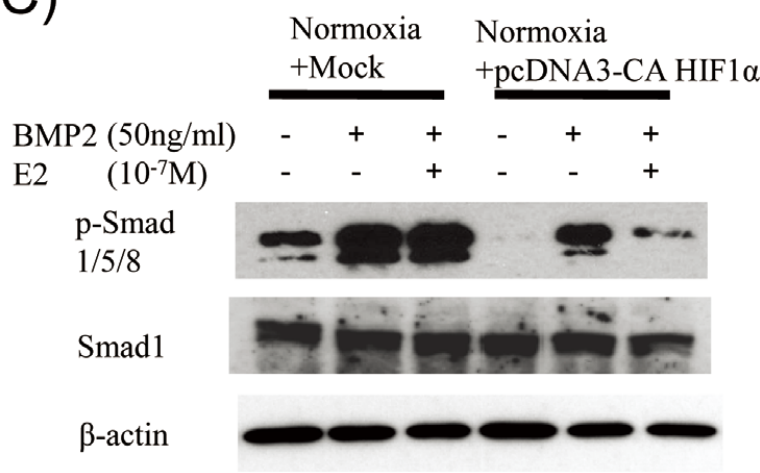

(E)

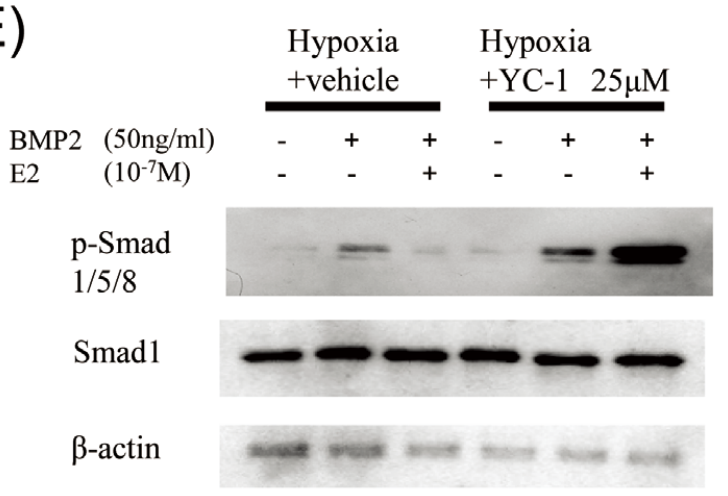

(B)

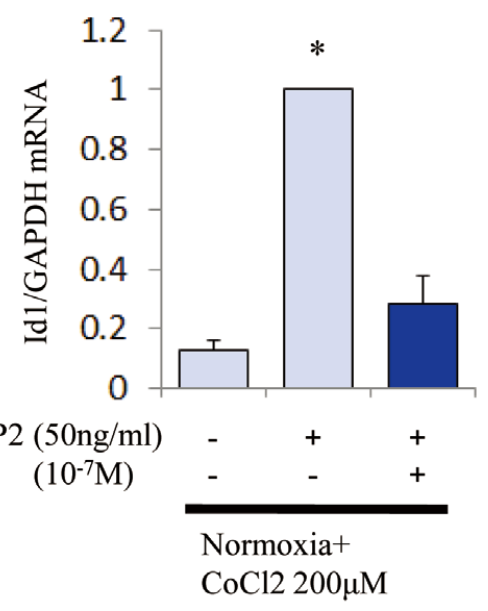

(D)

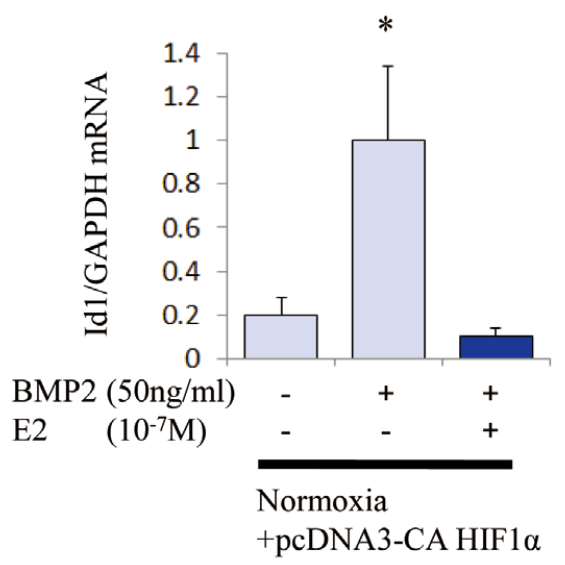

$(\mathrm{F})$

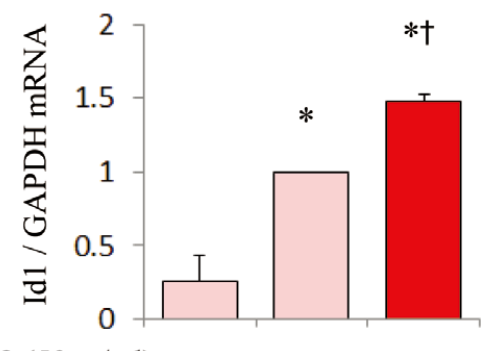

BMP2 (50ng/ml) - $\quad+\quad+\quad+$

E2 $\quad\left(10^{-7} \mathrm{M}\right)$

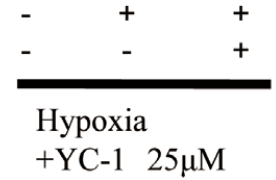

Figure 2. Effect of hypoxia-inducible factor (HIF)-1a regulation. (A,C,E) Western blot analysis for p-Smad1/5/8, Smad1 and $\beta$-actin proteins. (B,D,F) Quantitative RT-PCR of Id1 mRNA. Data were normalized by the expression of GAPDH. (A,B) Under normoxia with $\mathrm{CoCl} 2$, (A) p-Smad1/5/8 proteins and (B) Id1 mRNA were significantly increased with bone morphogenetic protein (BMP) 2 alone compared to vehicle treatment, and the addition of $\beta$-estradiol (E2) to BMP2 significantly decreased their expression compared with BMP2 alone. (C,D) Under normoxia with transfection with constitutively active (CA) HIF-1a plasmid, (C) p-Smad1/5/8 proteins and (D) Id1 mRNA were significantly increased with BMP2 alone compared to vehicle treatment, and the addition of E2 to BMP2 significantly decreased their expression compared to BMP2 alone. (E,F) Under hypoxia with YC-1, (E) p-Smad1/5/8 proteins and $(\mathbf{F})$ Id1 mRNA were significantly increased with BMP2 alone compared to vehicle treatment, and the addition of E2 to BMP2 further enhanced $\mathrm{p}-\mathrm{Smad} 1 / 5 / 8$ protein and Id $1 \mathrm{mRNA}$ expression compared to BMP2 alone. ${ }^{*} \mathrm{P}<0.05$ compared with vehicle alone. ${ }^{\dagger} \mathrm{P}<0.05$ compared with BMP2 alone. Results are representative of 3 separate experiments. 


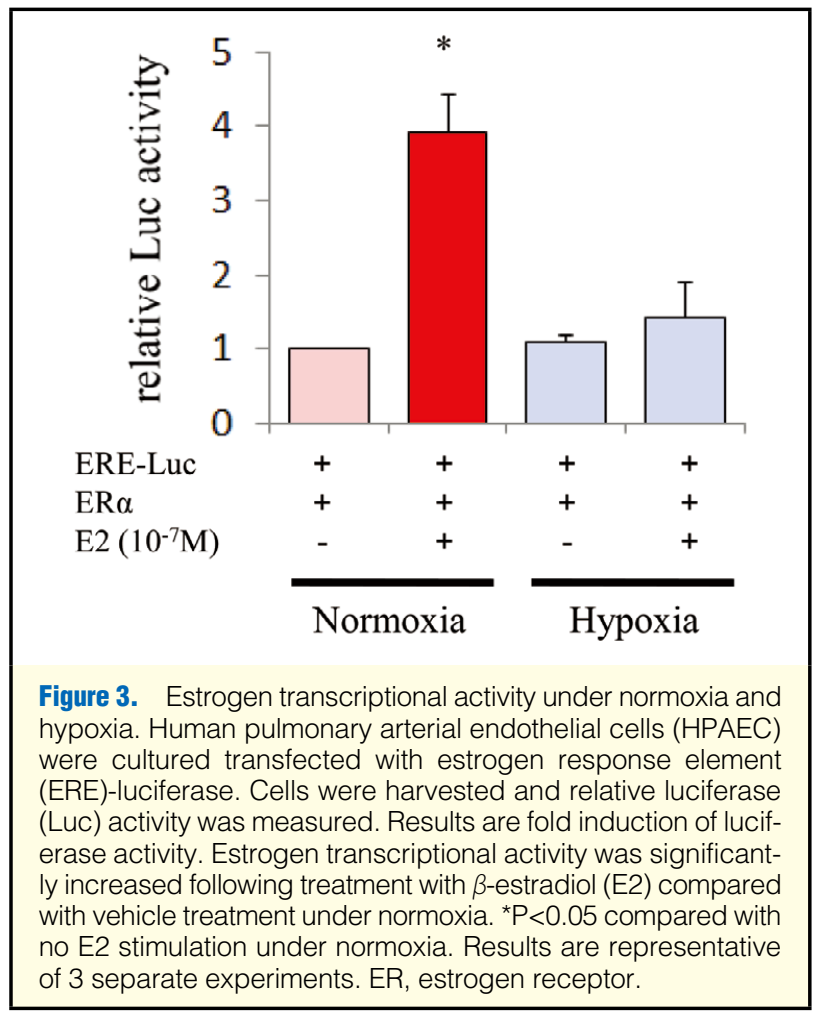

tive real-time RT-PCR was performed using TaqMan Gene expression products for human and rat Id1. The GAPDH gene was used as an internal standard for quantification (Applied Biosystems).

\section{Pretreatment With CHX}

To determine whether E2-induced alteration of p-Smad1/5/8 required de novo protein synthesis, subconfluent HPAEC were treated with $\mathrm{CHX}(4 \mu \mathrm{g} / \mathrm{ml})$, an inhibitor of protein translation, 30 min before stimulation with BMP2 and/or E2.

\section{Statistical Analysis}

All results are expressed as mean \pm SD. Statistically significant differences were analyzed on 1-way ANOVA followed by Tukey's multiple comparison post-hoc test. $\mathrm{P}<0.05$ was considered statistically significant.

\section{Results}

\section{Effects of Estrogen on BMP Signaling in HPAEC}

HPAEC were treated in a serum-free medium with or without $\mathrm{E} 2$ in the presence of BMP2 under either normoxia or hypoxia. Cell viability was not affected by estrogen and $\mathrm{O}_{2}$ concentration in this experiment. We had performed time course experiments at $0.5,2,6,12$, and $24 \mathrm{~h}$ after use of BMP2 and E2 and found significant changes at 12 and $24 \mathrm{~h}$. We decided to perform all experiments under $12 \mathrm{~h}$ incubation. In HPAEC (Figures 1A,B), the expression of $\mathrm{p}$-Smad1/5/8 proteins significantly increased following treatment with BMP2 alone compared with vehicle treatment, but no change was observed following use of E2 alone under both normoxia and hypoxia. The amount of $\mathrm{p}-\mathrm{Smad} 1 / 5 / 8$ proteins significantly increased by approximately $60 \%$ under normoxia $(\mathrm{P}=0.026)$ and decreased by approximately $60 \%$ under hypoxia $(\mathrm{P}=0.040)$ after the addition of both BMP2 and E2 compared with BMP2 alone.
Similarly, real-time RT-PCR showed that Id1 mRNA expression significantly increased following treatment with BMP2 alone compared with vehicle treatment, and no change was observed in the treatment with E2 alone under both normoxia and hypoxia (Figure 1C). Id1 mRNA expression was significantly enhanced under normoxia $(\mathrm{P}<0.01)$ and decreased under hypoxia $(\mathrm{P}<0.01)$ following the addition of both BMP2 and E2 compared with BMP2 alone.

\section{Effect of ICI 182,780}

We confirmed 2 distinct isoforms of ER, $\mathrm{ER} \alpha$ and $\mathrm{ER} \beta$, in HPAEC on RT-PCR (data not shown). To examine whether the effect of E2 on p-Smad1/5/8 expression was mediated by ER, we added the ER antagonist ICI 182,780 at $10^{-6} \mathrm{~mol} / \mathrm{L}$ concurrently with E2. Under normoxia, augmented expression of pSmad1/5/8 proteins with BMP2 and E2 treatment was inhibited by the addition of ICI 182,780 . Under hypoxia, decreased expression of $\mathrm{p}$-Smad1/5/8 proteins with BMP2 and E2 treatment was recovered by the addition of ICI 182,780 (Figures 1A,B). Similarly, under normoxia, significantly augmented Id1 mRNA expression with BMP2 and E2 treatment was inhibited by the addition of ICI 182,780. Under hypoxia, significantly decreased Id1 mRNA expression with BMP2 and E2 treatment was recovered by the addition of ICI 182,780 (Figure 1C). The effects of E2 on p-Smad1/5/8 and Id1 expression were inhibited by ICI 182,780 in HPAEC.

\section{Id1 Promoter Assay}

We examined the effects of E2 on transcriptional activity in BMP signaling by performing a -2.1-kb Id 1 promoter luciferase assay. In HPAEC (Figure 1D), Id1 transcriptional activity significantly increased following BMP2 alone compared with vehicle treatment, and no change was observed following the use of E2 alone under normoxia and hypoxia. Id1 transcriptional activity was increased by approximately 2.6-fold under normoxia $(\mathrm{P}<0.05)$ and decreased by 0.5 -fold under hypoxia $(\mathrm{P}<0.05)$ after the addition of both BMP2 and E2 compared with BMP2 alone.

\section{Effects of HIF-1a Activation}

We had examined HIF- $1 \alpha$ expression in HPAEC under $\mathrm{O}_{2}$ concentrations of $1 \%, 5 \%$, and $21 \%$. HIF- $1 \alpha$ expression was observed only in cells cultured under $1 \% \mathrm{O}_{2}$ (data not shown). We examined changes in $\mathrm{pSmad} 1 / 5 / 8$ and Id 1 expression when HIF- $1 \alpha$ expression was altered in HPAEC. To modify HIF- $1 \alpha$ expression, we used cobalt chloride $\left(\mathrm{CoCl}_{2}\right)$, plasmids containing constitutively active HIF- $1 \alpha$, or HIF- $1 \alpha$ inhibitor (YC-1). When HPAEC were cultured under normoxia with $\mathrm{CoCl}_{2}$ to prevent HIF- $1 \alpha$ degradation, the expression of $\mathrm{p}-\mathrm{Smad} 1 / 5 / 8$ proteins and Id1 mRNA was significantly increased with BMP2 alone compared to vehicle treatment, and the addition of E2 to BMP2 decreased their expression compared with BMP2 alone (Figures 2A,B). When HPAEC were cultured under normoxia with transient transfection of constitutively active HIF- $1 \alpha$, the expression of $\mathrm{p}-\mathrm{Smad} 1 / 5 / 8$ proteins and Id1 mRNA was significantly increased with BMP2 alone compared to vehicle treatment, and the addition of E2 to BMP2 decreased their expression compared to BMP2 alone (Figures 2C,D). In contrast, When HPAEC were cultured under hypoxia with YC-1, the expression of $\mathrm{p}-\mathrm{Smad} 1 / 5 / 8$ proteins and Id 1 mRNA was significantly increased with BMP2 alone compared to vehicle treatment, and the addition of E2 to BMP2 further increased p-Smad1/5/8 protein and Id 1 mRNA expression compared to BMP2 alone (Figures 2E,F). 


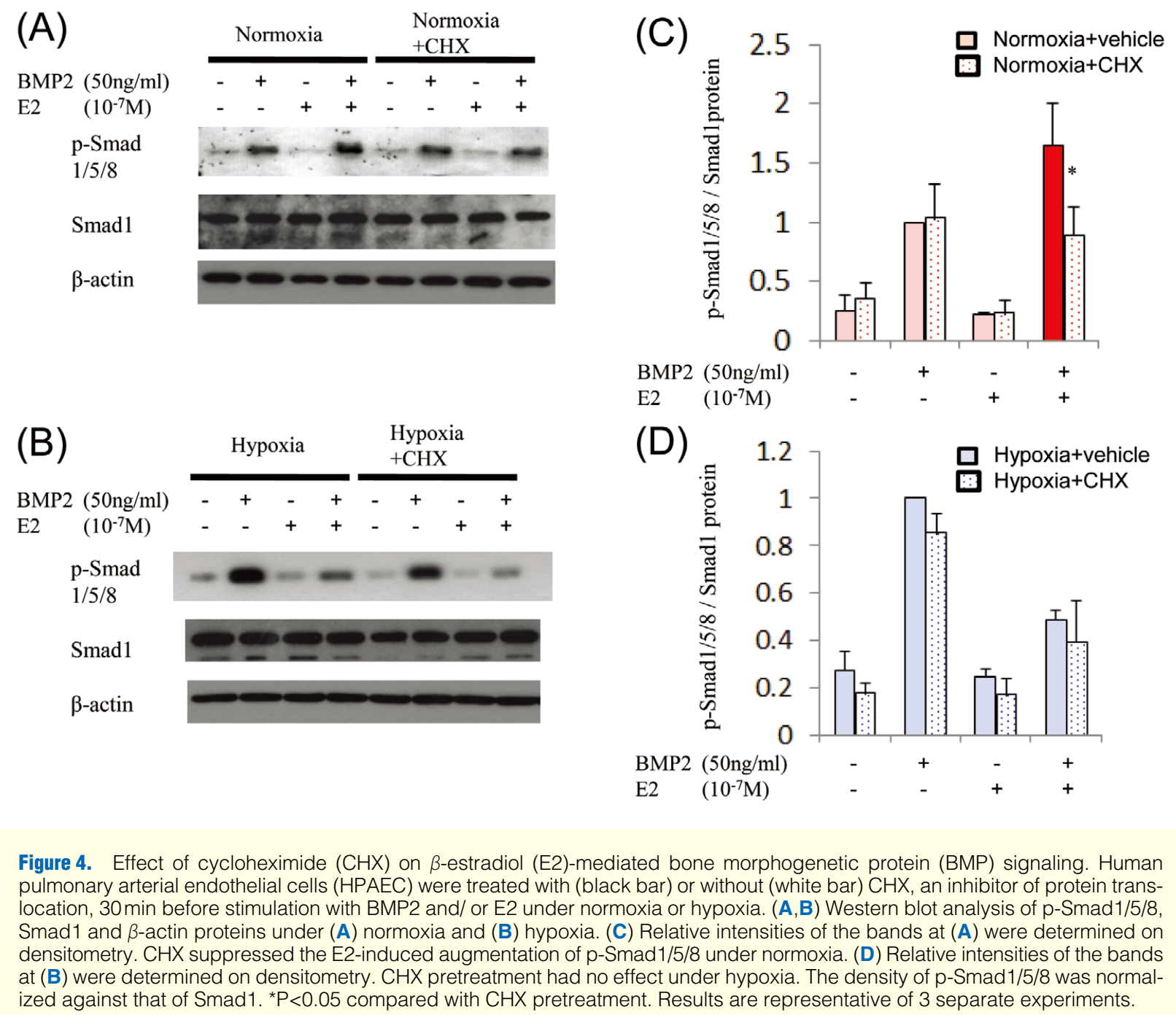

\section{ERE Reporter Assay}

To investigate whether the transcriptional activity of estrogen in HPAEC was altered under normoxia or hypoxia, we examined the ligand-dependent transcriptional activation of ER by performing an ERE-luciferase assay. The ERE-containing reporter plasmid was transiently transfected into HPAEC. After $12 \mathrm{~h}$ of treatment with E2, ERE-mediated transcription was increased by approximately 2.5 -fold under normoxia $(\mathrm{P}<0.05)$, but was not altered by E2 alone under hypoxia (Figure 3).

\section{Effect of CHX Pretreatment}

To ascertain whether an alteration of $\mathrm{p}-\mathrm{Smad} 1 / 5 / 8$ expression in response to estrogen was required for de novo protein synthesis, HPAEC were subjected to normoxia or hypoxia with or without CHX pretreatment. CHX suppressed the E2-induced augmentation of $\mathrm{p}$-Smad1/5/8 expression under normoxia (Figures $4 \mathrm{~A}, \mathrm{C}$ ). In contrast, $\mathrm{CHX}$ pretreatment had no effect under hypoxia (Figures 4B,D).

\section{Interactions Between BMP Signaling, ER, and HIF-1a}

To investigate interactions between BMP and E2-ER signaling, we tested the physical interaction between $\mathrm{p}-\mathrm{Smad} 1 / 5 / 8$ and ER and/or HIF- $1 \alpha$ in a co-immunoprecipitation experiment. As shown in Figures $\mathbf{5 A}, \mathbf{B}$, binding was observed among pSmad1/5/8, ER, and HIF- $1 \alpha$ proteins under hypoxia in cells treated with BMP2 and E2, whereas no binding was observed under normoxia. This binding was specifically localized in the nucleus (Figure 5C).

\section{Discussion}

Recent studies have found that multiple genetic factors are involved in the pathogenesis of PAH. Among them, dysregulated BMP signaling has been thought to play a key role in the onset and development of PAH. ${ }^{25,26}$ Here we elucidated the effect of estrogen on BMP signaling in HPAEC: (1) the effect of estrogen on BMP signaling in HPAEC differed depending on the $\mathrm{O}_{2}$ concentration; (2) the $\mathrm{O}_{2}$ concentration-dependent changes in BMP signaling produced by $\mathrm{E} 2$ are mediated by the level of HIF-1 $\alpha$ expression; and (3) entirely different mechanisms are involved in the degradation of HIF- $1 \alpha$ expression compared with the augmentation of HIF- $1 \alpha$ expression.

First, we showed that the effect of estrogen on BMP signaling in HPAEC differed depending on the $\mathrm{O}_{2}$ concentration. Under normoxia, the addition of E2 in the presence of BMP2 enhanced BMP signaling in HPAEC, whereas it attenuated 


\section{(A)}

$\begin{array}{ll}\text { BMP2 } & (50 \mathrm{ng} / \mathrm{ml}) \\ \text { E2 } & \left(10^{-7} \mathrm{M}\right)\end{array}$

IP: control IgG

WB: p-Smad $1 / 5 / 8$

IP: $\mathrm{ER} \alpha$

WB: p-Smad $1 / 5 / 8$
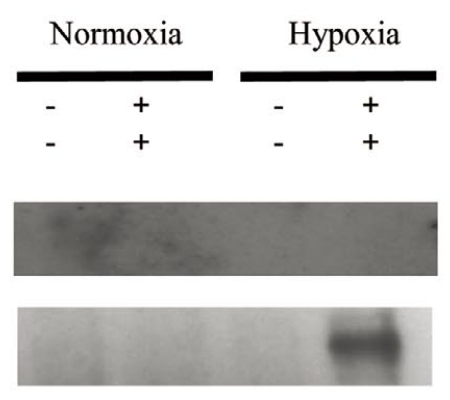

IP: $\mathrm{ER} \alpha$

WB: HIF-1 $\alpha$

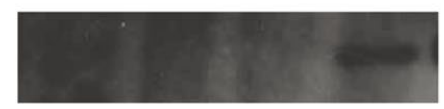

IP: $\mathrm{ER} \alpha$

WB: ER $\alpha$

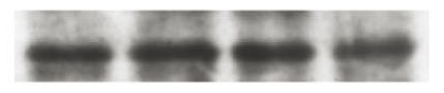

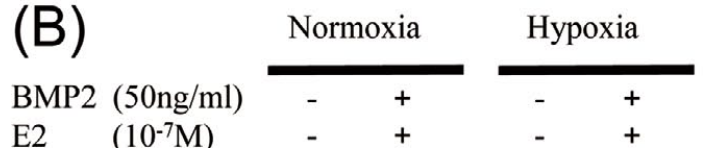

IP: control IgG

WB: p-Smad

$1 / 5 / 8$

IP: HIF-1 $\alpha$

WB: p-Smad

$1 / 5 / 8$

IP: HIF- $1 \alpha$

WB: ER $\alpha$

IP: HIF- $1 \alpha$

WB: HIF- $1 \alpha$

(C)

IP: HIF-1 $\alpha$
WB: p-Smad
$1 / 5 / 8$
IP: HIF-1 $\alpha$
WB:ER $\alpha$
IP: HIF-1 $\alpha$
WB:HIF-1 $\alpha$
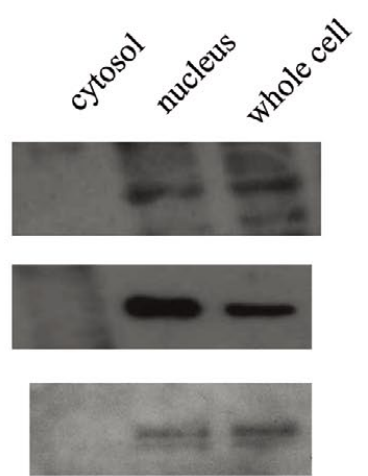

Figure 5. Interactions between p-Smad1/5/8, estrogen receptor (ER) a and hypoxia-inducible factor (HIF)-1a. Human pulmonary arterial endothelial cells (HPAEC) were cultured under normoxia or hypoxia for $24 \mathrm{~h}$, then were either left untreated or treated with bone morphogenetic protein (BMP) 2 and/or $\beta$-estradiol (E2) for $12 \mathrm{~h}$. (A) Total cell lysates were then immunoprecipitated (IP) with anti-ERa antibody and immunoblotted (WB) with anti-p-Smad1/5/8, anti-HIF-1a or anti-ERa antibody. (B) Total cell lysates were IP with anti-HIF-1 $a$ antibody and immunoblotted with anti-p-Smad1/5/8, anti-ERa or anti-HIF-1 $a$ antibody. Protein-protein binding was observed among p-Smad1/5/8, ER, and HIF-1a (A,B) under hypoxia treated with BMP2 and E2. (C) After treatment with BMP2 and E2 under hypoxia, lysates from cytosol extracts or nuclear extracts were prepared then IP with anti-HIF-1a antibody and immunoblotted with anti-p-Smad1/5/8, anti-ERa or anti-HIF-1a antibody. This binding was specifically localized in the nucleus. Results are representative of 3 separate experiments.

the signaling under hypoxia. These changes were inhibited by treatment with ICI 182,780, an ER antagonist. Thus, E2 acted through ER in these phenomenon. Previously, E2 has been shown to affect BMP signaling in various types of mammalian cell. Yamamoto et al reported that the addition of E2 in the presence of BMP2 suppressed BMP signaling in MCF-7 and HEK293 cells, ${ }^{27}$ whereas Paez-Pereda et al reported increases in BMP signaling in $\mathrm{GH} 3$ cells after the addition of $\mathrm{E} 2$ in the presence of BMP2. ${ }^{28}$ These studies also showed that additional treatment with the estrogen antagonist ICI 182,780 inhibited such changes in BMP signaling in vitro, suggesting that E2-induced changes in BMP signaling are mediated by ER. In addition, Helms et al reported the involvement of increased BMP signaling in the progression of ER-positive breast cancer. ${ }^{29}$ These observations clearly indicate the presence of crosstalk between BMP and estrogen signaling in various cell types. Here we have shown for the first time that the cross-talk in HPAEC changes its effect depending on $\mathrm{O}_{2}$ concentration.

Second, we focused on HIF- $1 \alpha$ expression in HPAEC be- cause HIF- $1 \alpha$ is an important $\mathrm{O}_{2}$-dependent transcription factor that regulates the expression of several genes in response to hypoxia. HIF-1 is a heterodimeric transcription factor consisting of an inducible $\alpha$-subunit and a constitutively expressed $\beta$-subunit. Previous studies demonstrated that HIF- $1 \alpha$ is strongly expressed in PAEC of PAH patients..$^{19,30}$ The present study indicated that the $\mathrm{O}_{2}$ concentration-dependent changes in BMP signaling induced by E2 may be associated with the expression of HIF- $1 \alpha$.

Next, we proposed that entirely different mechanisms were involved under normoxia or hypoxia regarding the changes in BMP signaling induced by E2. Under normoxia, the results of reporter assays using a plasmid containing ERE showed that estrogen transcriptional activity was significantly increased by the addition of E2. In addition, when de novo synthesized proteins were inhibited by $\mathrm{CHX}$ under normoxia, E2-augmented phosphorylation of Smad1/5/8 was significantly inhibited. These findings indicate that de novo synthesized proteins produced by E2-ER binding may facilitate BMP signaling under 
normoxia. In contrast, under hypoxia, immunoprecipitation experiment indicated that E2 in the presence of BMP2 caused the binding of p-Smad1/5/8 to ER and HIF- $1 \alpha$ in the nucleus. This is consistent with a report by Chun et al in which HIF- $1 \alpha$ induced by hypoxia was shown to be localized in the cell nucleus. ${ }^{31}$ There is neither a HIF- $1 \alpha$ - nor an ER-binding site in the Id1 promoter region, whereas the Smad-binding region is located approximately $-1 \mathrm{~kb}$ upstream from the Id 1 promoter. ${ }^{22}$ We propose the following possibilities: (1) the binding complex formed by p-Smad1/5/8, HIF- $1 \alpha$, and ER in the nucleus may inhibit $\mathrm{p}$-Smad1/5/8 binding to the promoter regions of the target genes such as Id1 and decrease BMP signal transduction; or (2) although p-Smad1/5/8 was transported to the nucleus, it might be rapidly exported from there for degradation after formation of the binding complex. Yamamoto et al confirmed the binding of Smad1 with ER in MCF-7 and HEK293 cells. ${ }^{27}$ Cho et al reported that $\mathrm{ER} \alpha$ downregulation under hypoxia involves protein-protein interactions between $\mathrm{ER} \alpha$ and HIF- $1 \alpha$ in MCF-7. ${ }^{32}$ Masuda et al showed that fibroblast growth factor (FGF) 8 increases the expression levels of estrogen and ER signaling, and inhibits Smad1/5/8 signal activity through suppression of the expression of BMPR2 in MCF-7 cells. ${ }^{33}$ Ito et al proposed that $\mathrm{ER} \alpha$ forms a protein complex with Smad and induces simultaneous degradation of these proteins through a ubiquitin-proteasome system to inhibit transforming growth factor (TGF) $\beta$ pathways in an estrogen-dependent manner. ${ }^{34}$ Further studies are needed to elucidate the detailed mechanisms underlying the alteration of BMP signaling under normoxia and hypoxia.

Austin et al reported that variations in estrogens and their metabolism could have adverse effects on PAH development with $B M P R 2$ mutations. ${ }^{35}$ White et al reported that female mice overexpressing the serotonin transporter (SERT+ mice) developed PAH, which was abolished by ovariectomy, but male SERT+ mice did not develop PAH. Long-term treatment with E2 progressed the PAH phenotype in ovariectomized female SERT + mice. ${ }^{36}$ Dempsie et al reported that female mice overexpressing the calcium-binding protein S100A4/Mts1 (Mts1+ mice) developed PAH and pulmonary vascular remodeling, whereas male Mts1+ mice remained unaffected. The development of plexiform-like lesions in Mts1+ mice was specific to the female. ${ }^{37}$ The aforementioned evidence is consistent with recent findings in human PAH. The present results explain, at least in part, the mechanism by which estrogen exerts contradictory effects in vivo, although the role of gender and/or estrogen in the development of PAH is still controversial.

\section{Conclusion}

Estrogen-induced changes in the BMP signaling in HPAEC altered, depending on the expression of HIF- $1 \alpha$, and different mechanisms may be involved in the estrogen effects on BMP signaling. Although further investigations are needed to examine the precise mechanisms involved, these in vitro data indicate that estrogen may act as an adverse factor in PAH development in some instances, which could explain at least in part the reason for the female predominance in idiopathic PAH.

\section{Acknowledgments}

We thank Dr K. Iwai (Kyoto University), Dr T. Katagiri (Saitama Medical University), Dr M. Makishima (Nihon University), Dr N. Tsumaki (Kyoto University), and Dr J. Yanagisawa (Tsukuba University) for providing advice and materials.

\section{Disclosures}

Name of grant: no financial assistance. Conflict of Interest: none declared.

\section{References}

1. Simonneau G, Robbins IM, Beghetti M, Channick RN, Delcroix M, Denton CP, et al. Updated clinical classification of pulmonary hypertension. J Am Coll Cardiol 2009; 54: S43-S54.

2. Fukumoto Y, Shimokawa H. Recent progress in the management of pulmonary hypertension. Circ J 2011; 75: 1801-1810.

3. Chida A, Shintani M, Nakayama T, Furutani Y, Hayama E, Inai K, et al. Missense mutations of the BMPR1B (ALK6) gene in childhood idiopathic pulmonary arterial hypertension. Circ J 2012; 76: 1501 1508 .

4. Fujiwara M, Yagi H, Matsuoka R, Akimoto K, Furutani M, Imamura $\mathrm{S}$, et al. Implications of mutations of activin receptor-like kinase 1 gene (ALK1) in addition to bone morphogenetic protein receptor II gene (BMPR2) in children with pulmonary arterial hypertension. Circ $J$ 2008; 72: 127-133.

5. Shintani M, Yagi H, Nakayama T, Saji T, Matsuoka R. A new nonsense mutation of SMAD8 associated with pulmonary arterial hypertension. J Med Genet 2009; 46: 331-337.

6. International PPH Consortium, Lane KB, Machado RD, Pauciulo MW, Thomson JR, Phillips JA 3rd, Loyd JE, et al. Heterozygous germline mutations in BMPR2, encoding a TGF-beta receptor, cause familial primary pulmonary hypertension. Nat Genet 2000; 26: 81-84.

7. Machado RD, Aldred MA, James V, Harrison RE, Patel B, Schwalbe EC, et al. Mutations of the TGF-beta type II receptor BMPR2 in pulmonary arterial hypertension. Hum Mutat 2006; 27: 121 - 132.

8. Thomson JR, Machado RD, Pauciulo MW, Morgan NV, Humbert M, Elliott GC, et al. Sporadic primary pulmonary hypertension is associated with germline mutations of the gene encoding BMPR-II, a receptor member of the TGF-beta family. J Med Genet 2000; 37: 741-745.

9. Atkinson C, Stewart S, Upton PD, Machado R, Thomson JR, Trembath $\mathrm{RC}$, et al. Primary pulmonary hypertension is associated with reduced pulmonary vascular expression of type II bone morphogenetic protein receptor. Circulation 2002; 105: 1672-1678.

10. Austin ED, Loyd JE, Phillips JA 3rd. Genetics of pulmonary arterial hypertension. Semin Respir Crit Care Med 2009; 30: 386-398.

11. Rosenzweig EB, Morse JH, Knowles JA, Chada KK, Khan AM, Roberts KE, et al. Clinical implications of determining BMPR2 mutation status in a large cohort of children and adults with pulmonary arterial hypertension. J Heart Lung Transplant 2008; 27: 668-674.

12. Beretta L, Caronni M, Origgi L, Ponti A, Santaniello A, Scorza R. Hormone replacement therapy may prevent the development of isolated pulmonary hypertension in patients with systemic sclerosis and limited cutaneous involvement. Scand J Rheumatol 2006; 35: $468-$ 471.

13. Lahm T, Crisostomo PR, Markel TA, Wang M, Weil BR, Novotny $\mathrm{NM}$, et al. The effects of estrogen on pulmonary artery vasoreactivity and hypoxic pulmonary vasoconstriction: Potential new clinical implications for an old hormone. Crit Care Med 2008; 36: 2174-2183.

14. Miyazono K, Kamiya Y, Morikawa M. Bone morphogenetic protein receptors and signal transduction. J Biochem 2010; 147: 35-51.

15. Takahashi K, Kogaki S, Matsushita T, Nasuno S, Kurotobi S, Ozono $\mathrm{K}$. Hypoxia induces alteration of bone morphogenetic protein receptor signaling in pulmonary artery endothelial cell. Pediatr Res 2007; 61: $392-397$.

16. Richter A, Yeager ME, Zaiman A, Cool CD, Voelkel NF, Tuder RM. Impaired transforming growth factor-beta signaling in idiopathic pulmonary arterial hypertension. Am J Respir Crit Care Med 2004; 170: $1340-1348$.

17. Cool CD, Stewart JS, Werahera P, Miller GJ, Williams RL, Voelkel $\mathrm{NF}$, et al. Three-dimensional reconstruction of pulmonary arteries in plexiform pulmonary hypertension using cell-specific markers: Evidence for a dynamic and heterogeneous process of pulmonary endothelial cell growth. Am J Pathol 1999; 155: 411-419.

18. Morty RE, Nejman B, Kwapiszewska G, Hecker M, Zakrzewicz A, Kouri FM, et al. Dysregulated bone morphogenetic protein signaling in monocrotaline-induced pulmonary arterial hypertension. Arterioscler Thromb Vasc Biol 2007; 27: 1072-1078.

19. Tuder RM, Chacon M, Alger L, Wang J, Taraseviciene-Stewart L, Kasahara Y, et al. Expression of angiogenesis-related molecules in plexiform lesions in severe pulmonary hypertension: Evidence for a process of disordered angiogenesis. J Pathol 2001; 195: 367-374.

20. Hiraga T, Kizaka-Kondoh S, Hirota K, Hiraoka M, Yoneda T. Hypoxia and hypoxia-inducible factor-1 expression enhance osteolytic bone metastases of breast cancer. Cancer Res 2007; 67: 4157-4163.

21. Kelly BD, Hackett SF, Hirota K, Oshima Y, Cai Z, Berg-Dixon S, et 
al. Cell type-specific regulation of angiogenic growth factor gene expression and induction of angiogenesis in nonischemic tissue by a constitutively active form of hypoxia-inducible factor 1. Circ Res 2003; 93: 1074-1081.

22. Katagiri T, Imada M, Yanai T, Suda T, Takahashi N, Kamijo R. Identification of a BMP-responsive element in Id1, the gene for inhibition of myogenesis. Genes Cells 2002; 7: 949-960.

23. Janowski BA, Willy PJ, Devi TR, Falck JR, Mangelsdorf DJ. An oxysterol signalling pathway mediated by the nuclear receptor LXR alpha. Nature 1996; 383: 728-731.

24. Kawai M, Namba N, Mushiake S, Etani Y, Nishimura R, Makishima $\mathrm{M}$, et al. Growth hormone stimulates adipogenesis of 3T3-L1 cells through activation of the Stat5A/5B-PPARgamma pathway. J Mol Endocrinol 2007; 38: 19-34.

25. Rubin LJ. Primary pulmonary hypertension. N Engl J Med 1997; 336: $111-117$.

26. Humbert M, Morrell NW, Archer SL, Stenmark KR, MacLean MR, Lang IM, et al. Cellular and molecular pathobiology of pulmonary arterial hypertension. J Am Coll Cardiol 2004; 43: 13S-24S.

27. Yamamoto T, Saatcioglu F, Matsuda T. Cross-talk between bone morphogenic proteins and estrogen receptor signaling. Endocrinology 2002; 143: 2635-2642.

28. Paez-Pereda M, Giacomini D, Refojo D, Nagashima AC, Hopfner U, Grubler Y, et al. Involvement of bone morphogenetic protein 4 (BMP4) in pituitary prolactinoma pathogenesis through a Smad/estrogen receptor crosstalk. Proc Natl Acad Sci USA 2003; 100: 1034-1039.

29. Helms MW, Packeisen J, August C, Schittek B, Boecker W, Brandt $\mathrm{BH}$, et al. First evidence supporting a potential role for the BMP/ SMAD pathway in the progression of oestrogen receptor-positive breast cancer. J Pathol 2005; 206: 366-376.
30. Fijalkowska I, Xu W, Comhair SA, Janocha AM, Mavrakis LA, Krishnamachary B, et al. Hypoxia inducible-factorlalpha regulates the metabolic shift of pulmonary hypertensive endothelial cells. Am J Pathol 2010; 176: 1130-1138.

31. Chun YS, Choi E, Yeo EJ, Lee JH, Kim MS, Park JW. A new HIF-1 alpha variant induced by zinc ion suppresses HIF-1-mediated hypoxic responses. J Cell Sci 2001; 114: 4051-4061.

32. Cho J, Kim D, Lee S, Lee Y. Cobalt chloride-induced estrogen receptor alpha down-regulation involves hypoxia-inducible factor-1alpha in MCF-7 human breast cancer cells. Mol Endocrinol 2005; 19: $1191-1199$.

33. Masuda H, Otsuka F, Matsumoto Y, Takano M, Miyoshi T, Inagaki $\mathrm{K}$, et al. Functional interaction of fibroblast growth factor-8, bone morphogenetic protein and estrogen receptor in breast cancer cell proliferation. Mol Cell Endocrinol 2011; 343: 7-17.

34. Ito I, Hanyu A, Wayama M, Goto N, Katsuno Y, Kawasaki S, et al. Estrogen inhibits transforming growth factor beta signaling by promoting Smad2/3 degradation. J Biol Chem 2010; 285: 14747-14755.

35. Austin ED, Cogan JD, West JD, Hedges LK, Hamid R, Dawson EP, et al. Alterations in oestrogen metabolism: Implications for higher penetrance of familial pulmonary arterial hypertension in females. Eur Respir J 2009; 34: 1093-1099.

36. White K, Dempsie Y, Nilsen M, Wright AF, Loughlin L, MacLean MR. The serotonin transporter, gender, and 17beta oestradiol in the development of pulmonary arterial hypertension. Cardiovasc Res 2011; 90: 373-382.

37. Dempsie Y, Nilsen M, White K, Mair KM, Loughlin L, Ambartsumian $\mathrm{N}$, et al. Development of pulmonary arterial hypertension in mice over-expressing S100A4/Mts1 is specific to females. Respir Res 2011; 12: 159 . 